\title{
Environmental Strategies in Areas Affected by Ash from Large Combustion Plants
}

\author{
Constantin Cotiga ${ }^{1, a}$, Olimpia Ghermec ${ }^{2, b^{*}}$, Ionela BUCSE ${ }^{2, c}$, Dumitru Țugui ${ }^{3, d}$ \\ ${ }^{1}$ University of Craiova, Faculty of Agriculture end of Horticulture, Agricultural and Forestry \\ Technology Department, Craiova, Romania
}

${ }^{2}$ University of Craiova, Faculty of Mechanics, Department of Engineering and Management of Technological Systems, Drobeta Turnu Severin, Romania

${ }^{3}$ SC Agro Bioforce SRL, Romania

acotigaconstantin@yahoo.com, bolimpia_ghermec@yahoo.com, cbucse_ionela@yahoo.com, tuguidumitru69@yahoo.com

Keywords: strategy, pollution, ash, fertilization

\begin{abstract}
The great extent of industrialization in the world can have serious repercussions on the environment. Damage to agricultural ecosystems is produced not only by the industrial centers or mining, but also by the ash resulting from burning coal in combustion plants. Restoration in the agricultural exploitation of lands degraded by industry and the areas under deposits of polluting fly ash is a key objective that lies in the attention of scientists for better use of the entire land fund. The experimental results obtained in this sense are particularly promising. Most of the research went on using the ash dumps by biological fixation with vegetation and by binding and using a specific agricultural technique. Therefore, recultivation and fixation of fly ash dumps targets to protect the environment and reduce air pollution with dust from the ashes, i.e. to harness economic areas occupied by dumps.
\end{abstract}

\section{Introduction}

Returning into the agricultural circuit fields degraded by industry and also surfaces occupied by storehouses that pollute with ash from combustion plants represents a basic objective scientists pay attention to in order to make proper use of the entire land fund $[2,4,7]$.

The experimental results obtained in this regard are promising.

Most researchers have decided to use dumps through biological fixation and also by covering, respectively using a specific agricultural technique $[1,3]$.

Therefore, recultivation and fixation of fly ash dumps targets to protect the environment and reduce air pollution with dust from the ashes, i.e. to harness economic areas occupied by dumps [5].

\section{Material and experimentation method}

The material used when experimenting was obtained from the National Institute of Research Agricultural Development-Fundulea and from the units of scientific research from the historical area of Oltenia, Romania.

The experiences were put in the experimental field situated on the ash dumps from IşalniţaCraiova and were observed in the interval 2010-2012.

\section{Results and discussion}

If we are to analyze the results obtained and presented in fig. 1 referring to the effect of fertilization with nitrogen on the production of biomass in the case of the temporary meadow taken into the study in an average of 3 years, the following conclusions can be drawn: depending on the level of fertilization with nitrogen, the quantity of biomass grows in direct proportion with the enlargement of the dosage, from $44.3 \mathrm{t} / \mathrm{ha} \mathrm{m}$. v. (N 0) to $72.5 \mathrm{t} / \mathrm{ha} \mathrm{m}$. v. (N 180). 


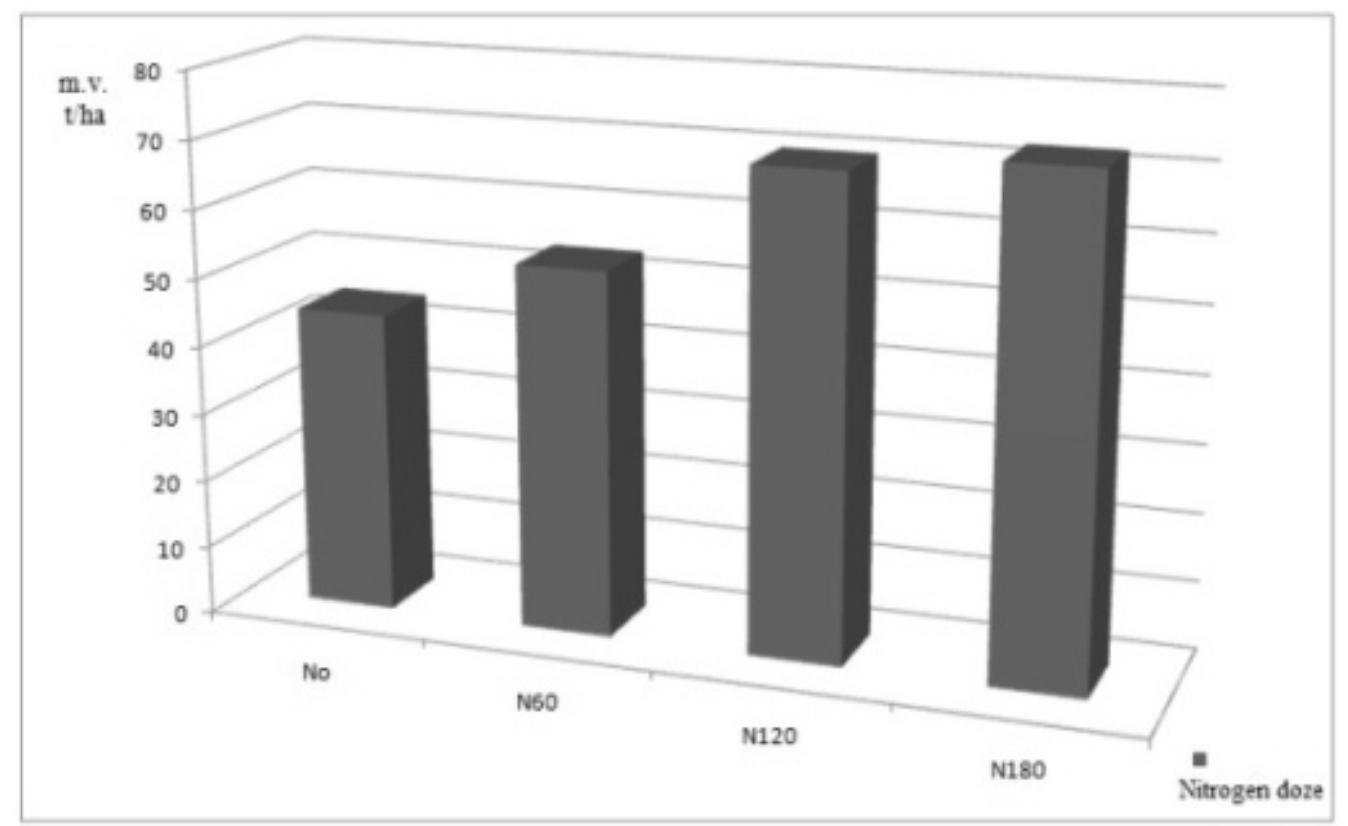

Fig. 1 The effect of the fertilization with nitrogen on the production of green mass of the temporary meadow (average of 3 years)

However, we can't but observ that a field of biomass of $69.9 \mathrm{t} / \mathrm{ha} \mathrm{m}$. v., very close to the maximum one, was realized with a smaller dosage of nitrogen, which, from an economic point of view, is more advantageous.

In fig. 2 is presented the effect of organic-mineral fertiilizatio on the prodction of biomass in the case of the temporary meadow in an average of 3 years, based upon which we can see the substantial effect of the organic fertilization on the level of the harvest, on its quality and on realizing a well-clotted grassy carpet.

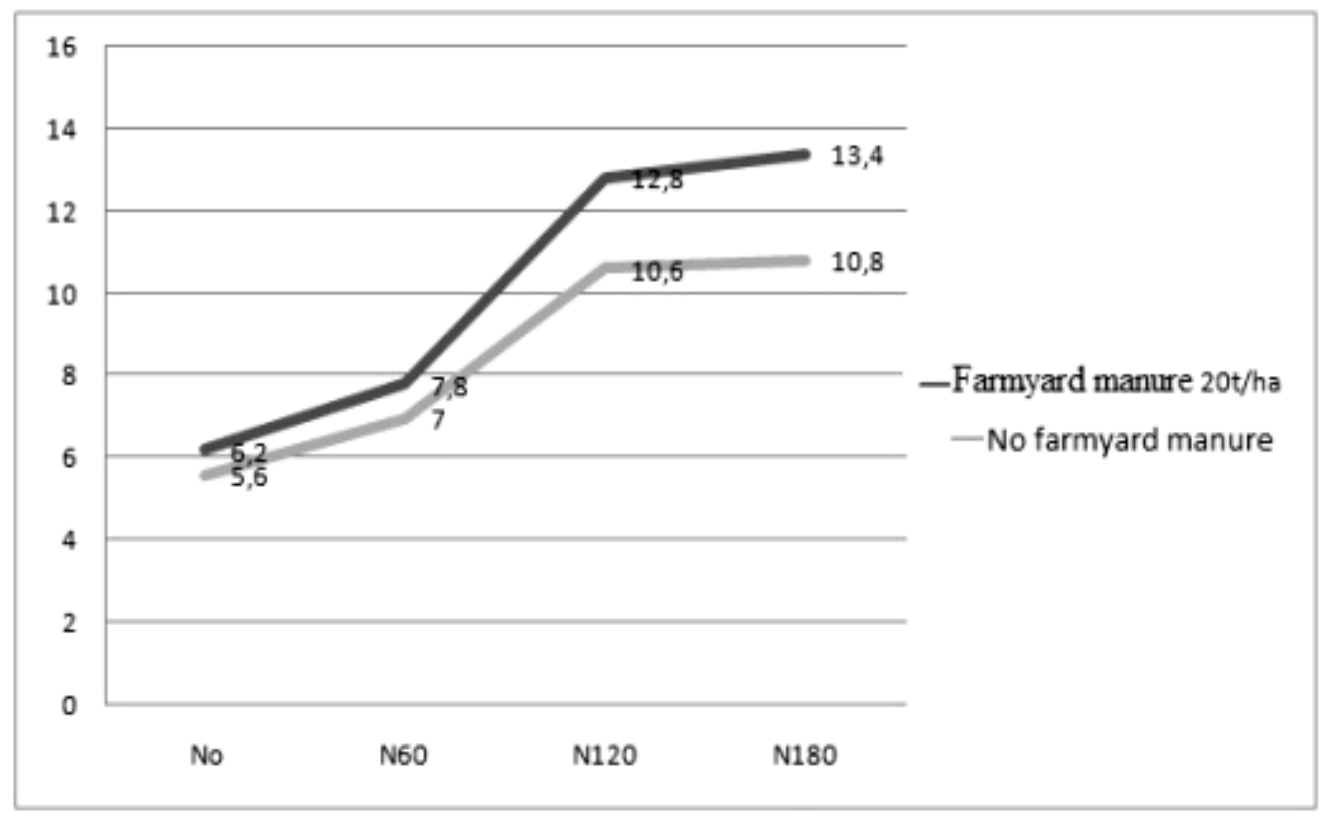

Fig. 2 The effect of the organic-mineral fertilization on the production of biomass of the temporary meadow (average of 3 years)

If we refer to the dynamic of the biomass oriduction on cycles of exploitation in average during the three years of experimenting, we can see a good repartition of the biomass, which depends greatly on the level of fertilization with nitrogen. 
The optimul level of fertilization with nitrogen that can be highlighted in this case is N150.

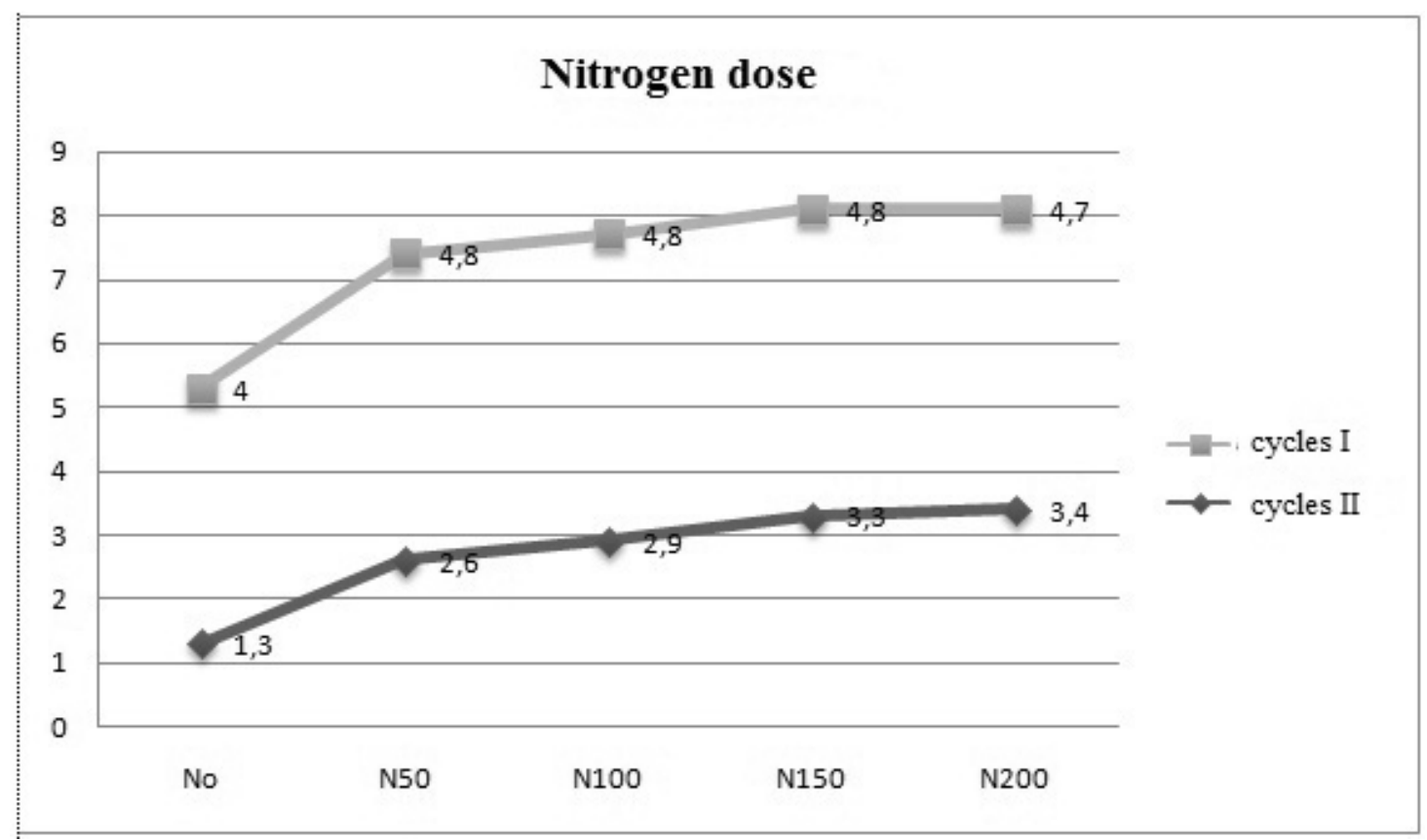

Fig. 3 Dynamics of production of dry matter per sew the 3 year average (P50 variant)

In what regards the influence of phosphorus on the production of biomass, in average during the three years (fig. 4) we can see the substantial effect rpoduced by phosphorus in P50 dosage as compared to no phosphorus at all, which proves that power plant ash needs the constribution of phosphorus in order to be capitalized [6].

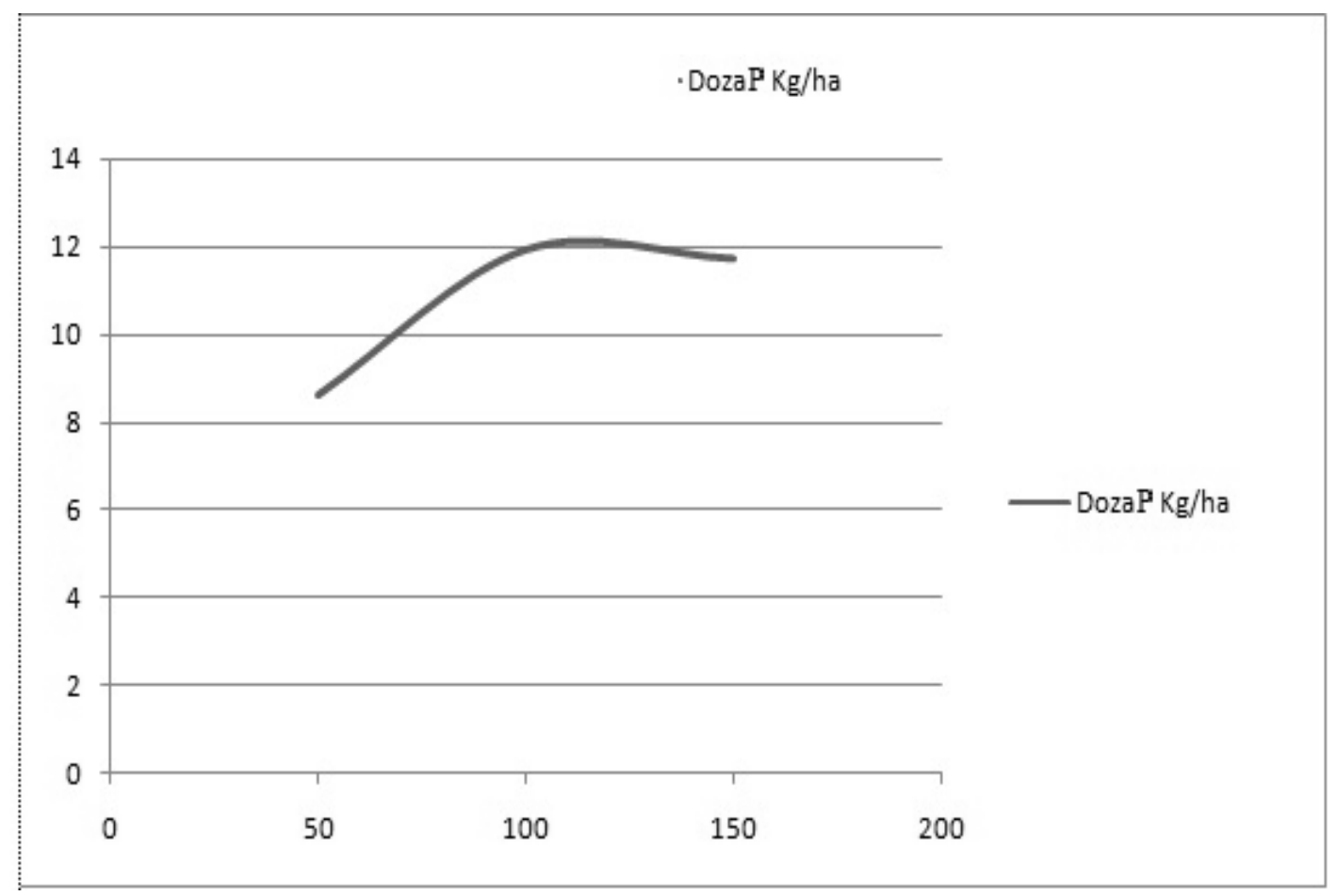

Fig. 4 Influence of phosphorus on the production of biomass 


\section{Conclusions}

Based upon the results obtained in average during the three years of experimenting, the productivity of a number of varieties of legume and perennial grasses, on dumps of ash at the experimental center Işalniţa-Craiova, we can formulate the following conclusions and recommendations:

1. The pure cultures of legume and perennial grasses manage to fallow good the ash dump from the first year, except the legume, in which case the percentage of participation is decreased starting with the third year of exploitation.

2. The mixtures of legume and perennial grasses highly contribute to the existence and the persistance of a grassy carpet, better clotted than the pute cultures and this is why we cannot consider it a real obstacle for dissipating the deposited ash.

3. It is advisable that the fallow of the dumps be made in spring, as early as possible $\left(1{ }^{\text {st }}-15^{\text {th }}\right.$ of March), so that it can benefit from the water accumulated during the cold season.

4. To avoid the phenomenon of pollution caused by the scattering of ash lodged in dumps and for using them with efficiency, we recommend put them into agricultural circuite.

5. Perennial forage grasses, especially Dactylis glomerata, Bromus inermis and Lolium perenne adapt well to environmental conditions in the experimental area.

6. Due to the scarcity of nitrogen in an assimilable form, organic and mineral fertilization is necessary to stimulate the lush development of plants.

7. One component of the core technology determining the success of lying fallow the ash dump is to ensure moisture, especially in the first stage.

8. Once the temporary meadows are set up and in combination with their rational exploitation, a substantial reduction of the pollutant effect produced by the drifting ash can be observed and the deficit of biomass in the area can also be completed.

9. A special attention should be paid in the future to the creation of green protection screens, in whose composition enter forestry species such as acacia, poplar, etc., which contribute substantially to reduce the drafting of ash and maintaining water in the ecosystem.

\section{References}

[1] Bărbulescu C. and collab., The culture of meadows and of fodder plants, Didactic and Pedagogical Publishig House, Bucharest, (1991).

[2] Cotigă C., The ecology and the protection of the environment, Sitech Publishing House, Craiova, (2011).

[3] Cotigă C., The culture of meadows and of fodder plants, volumes I and II, Sitech Publishing House, Craiova, (2012).

[4] Cotigă C., Environmental protection and sustainable development. Manuscript, (2013).

[5] Ciobanu M., Mazilu M., Diminescu M. „The study of the environment quality in the Mehedinti county - heavy metals, sediments and particulates" The Seventh International Congress in Materials Science and Engineering, Mai 28-31, Iasi, Romania, (2009).

[6] Moga I. and collab., Perrenial fodder plants, S.R.R. Academia Publishing House (1983).

[7] Popescu I.I. and collab., Fighting pollution produced by power plant ash through cultivation of the dumps with agricultural plants. Ecology and protection of the ecosystems, (1996). 